\title{
O socioambientalismo e o turismo solidário no Complexo do Alemão (RJ, Brasil)
}

\author{
Socioenvironmentalism and solidarity tourism in Complexo \\ do Alemão (Rio de Janeiro, Brazil)
}

Rafael Ângelo Fortunato, Elza Neffa

\begin{abstract}
RESUMO
O artigo analisa como o turismo solidário está sendo desenvolvido no Complexo do Alemão e a apropriação da proposta pelos atores sociais locais. O entendimento do contexto no qual as ações de turismo ocorrem, à luz da fenomenologia, é fundamental para a identificação dos entraves e das potencialidades existentes no processo de implementação do turismo solidário neste espaço, tendo em vista a pretensão de se incluir, no processo de pesquisa, os atores sociais, de forma interativa, e de estabelecer compromissos dos pesquisadores com a produção do conhecimento e com o desenvolvimento da sociedade, o que exige a adoção da metodologia pesquisa-ação transdisciplinar, por esta abordagem se inserir numa perspectiva humanista da ciência. O entendimento da pesquisa-ação como estratégia de conhecimento voltada para a resolução de problemas da realidade justifica sua opção e consolida a perspectiva de envolver pesquisadores e atores em processos de participação ativa, de reconhecimento da multidimensionalidade da realidade, de identificação e hierarquização de problemas, de mediação de conflitos, de desenvolvimento da episteme complexa dos sujeitos e de construção de ações com base em princípios ético-solidários. As relações complexas que o turismo estabelece com outras iniciativas existentes no Complexo do Alemão, de caráter socioambiental, apontam os indicadores do turismo solidário como relevantes para a análise do fenômeno turístico enquanto fator contribuinte do desenvolvimento local. Neste artigo, destaca-se parte desse processo, cujas ações resultaram no início do processo de implantação do turismo solidário no Complexo do Alemão, na divulgação de um documentário e na apresentação das dificuldades e dos conflitos que os moradores vivenciam na luta pela sua emancipação. Atualmente, um grupo mobilizado aposta no turismo solidário como forma de promover a gestão do turismo, os aprendizados mútuos baseados em saberes locais e o desenvolvimento sustentável de comunidades.
\end{abstract}

PALAVRAS-CHAVE: Turismo Solidário; Socioambientalismo; Participação; Desenvolvimento Local. 


\section{ABSTRACT}

The article examines how solidarity tourism is being developed at the Complexo do Alemão and how the social actors are taking ownership of this proposal. Understanding the context in which the tourism occur, in light of phenomenology, is essential to identify obstacles and existing potentialities in the implementation of solidarity tourism in this location. The research includes the social actors interactively in its process and establishes commitment of the researchers with the production of knowledge and the development of society. In order to achieve this, transdisciplinary actionresearch methodology is used because this approach inserts a humanist perspective of science. The understanding of action-research as a strategy for building knowledge which is focused on solving problems of reality justifies this choice of method and consolidates the perspective of involving researchers and actors in the process of active participation, recognizing the multidimensional nature of reality, identifying and prioritizing problems, mediating conflicts, developing subject's complex episteme and building actions based on ethical and solidarity principles. The complex relationships that tourism establishes with other existing initiatives of a socioenvironmental nature in the Complexo do Alemão points towards the solidarity tourism indicators as relevant to the analysis of the tourism phenomenon as a contributing factor of local development. In this article, we highlight part of this process, whose actions resulted in the early deployment of solidarity tourism in Complexo do Alemão, publicize a documentary and present the difficulties and conflicts that residents experience in their struggle for emancipation. Currently, a mobilized group bet in solidarity tourism as a way to promote tourism management, mutual learning based on local knowledge and the sustainable development of communities.

KEYWORDS: Solidarity Tourism; Socioenvironmentalism; Participation; Local Development.

\section{Introdução}

O turismo destaca-se como elemento central no processo de geração de divisas, pois é considerado um dos segmentos econômicos que mais cresce em todo o mundo. Nesse contexto, o Rio de Janeiro ganha evidencia no país pois, considerada a "porta de entrada" dos turistas internacionais, esta cidade sediará a Copa do Mundo em 2014 e as Olimpíadas em 2016, o que contribuirá para aumentar o fluxo de turistas internacionais, inclusive nas favelas cariocas.

Desde a Conferência Rio-92, as favelas recebem turistas e, atualmente, sofrem influência das políticas públicas de segurança do governo do Estado do Rio de Janeiro com a implantação de Unidades de Polícia Pacificadora (UPP), em 2008, que permitiu o incremento de investimentos na atividade turística e estimulou a implementação do turismo solidário no Complexo do Alemão, após o processo de pacificação ocorrido em 2012.

Este artigo apresenta a trajetória de um trabalho empírico realizado nesta localidade em parceria com a Rede Brasilidade Solidária ${ }^{1}$ configurando-se, portanto, no campo da pesquisa-ação. 
Para Thiollent, a pesquisa-ação refere-se a

um tipo de pesquisa social com base empírica que é concebida e realizada em estreita associação com uma ação ou com a resolução de um problema coletivo e no qual os pesquisadores e os participantes representativos da situação ou do problema estão envolvidos de modo cooperativo ou participativo (2011, p.20).

Este trabalho adota a concepção da pesquisa-ação transdisciplinar, formulada por Palavizini (2012, p.70), que a distingue da pesquisa participante, por abranger, além da participação das pessoas, "um papel ativo na reflexão dos problemas levantados, na definição conjunta das ações e no acompanhamento e avaliação do processo".

Em março de 2012, quando um dos pesquisadores interagiu com atores sociais locais interessados em desenvolver a atividade turística, 0 processo de implementação do turismo solidário teve início no Complexo do Alemão utilizando-se a fenomenologia como uma lupa que permitia a identificação e a socialização dos significados atribuídos pelos atores sociais ao processo de desenvolvimento dessa modalidade de turismo.

As análises com a orientação da fenomenologia visam a apreender a essência do fenômeno (HUSSERL, 2000) por meio da descrição dos casos ocorridos no campo de pesquisa. De acordo com tal perspectiva teórica, o pesquisador, ao ler os discursos do sujeito é orientado por um sentido, por uma busca de significados que ele intui ou detecta. As proposições ontológicas e epistemológicas representam as concepções sobre 0 fenômeno. As percepções que os sujeitos têm da sua experiência vivida passam a constituir os dados da pesquisa ou as "unidades de significado" que compõem os elementos estruturais do fenômeno (MACHADO, 1994, p.45).

Ao mapear as unidades de significado atribuídas ao turismo solidário e as ações de caráter socioambiental, as traduções locais para esses campos evidenciam-se e contribuem para as reflexões sobre o processo de desenvolvimento turístico em "comunidades". Essas reflexões abrangem o socioambientalismo e o desenvolvimento local e, portanto, relacionam-se às ações sociais e ambientais para o desenvolvimento, que se apresentam como "pano de fundo", contexto, no qual o projeto de turismo solidário é proposto.

Pensado como uma nova estratégia de desenvolvimento socioambiental pautado, ao mesmo tempo, nos saberes locais e na ideia de co-aprendizagem e participação, essa modalidade de turismo contribui para o início de um processo capaz de trazer melhorias para as condições socioambientais das localidades, na medida em que os atores sociais (turistas, moradores, pesquisadores) podem vivenciar processos complexos da paisagem, participar da problemática local, trocar experiências/saberes/recursos com a sociedade, produzir conhecimento no envolvimento com um processo educacional de aprendizagem mútua, que agrega a valorização da percepção da multidimensionalidade da realidade e 
a ampliação da consciência dos envolvidos com base na reflexão ética, e absorver esses elementos como estruturantes de ações coletivas para tomadas de decisão e de compromisso com a transformação da realidade.

As análises sobre o socioambientalismo brasileiro como pano de fundo para o desenvolvimento do turismo solidário no Complexo do Alemão, e sobre o modo como os cidadãos se apropriam das ações socioambientais realizadas nas favelas, subsidiam a ampliação do campo de possibilidades de práticas participativas que são relevantes quando se pensa na superação de problemas socioambientais e nas diretrizes do turismo solidário representadas pelos 6 V's (Visitação, Vivências, Vendas, Vínculos, Veiculação e Validação), aqui apresentadas, com maior profundidade, no decorrer do artigo.

\section{Sobre o Complexo do Alemão}

O Complexo do Alemão localiza-se na zona norte do município do Rio de Janeiro e é considerado uma das regiões mais violentas da cidade. O nome "Alemão" resulta da presença de um colono polonês, proprietário de grande porção de terra na Serra da Misericórdia, na década de 1920. Mais tarde, na década de 50, as terras foram vendidas e o território tornou-se um dos polos industriais mais importantes do Rio de Janeiro. Esse período iniciou a formação do Complexo do Alemão (Figura 1) que hoje possui uma população de 69.143 habitantes (IBGE, 2010) espalhada em treze favelas.

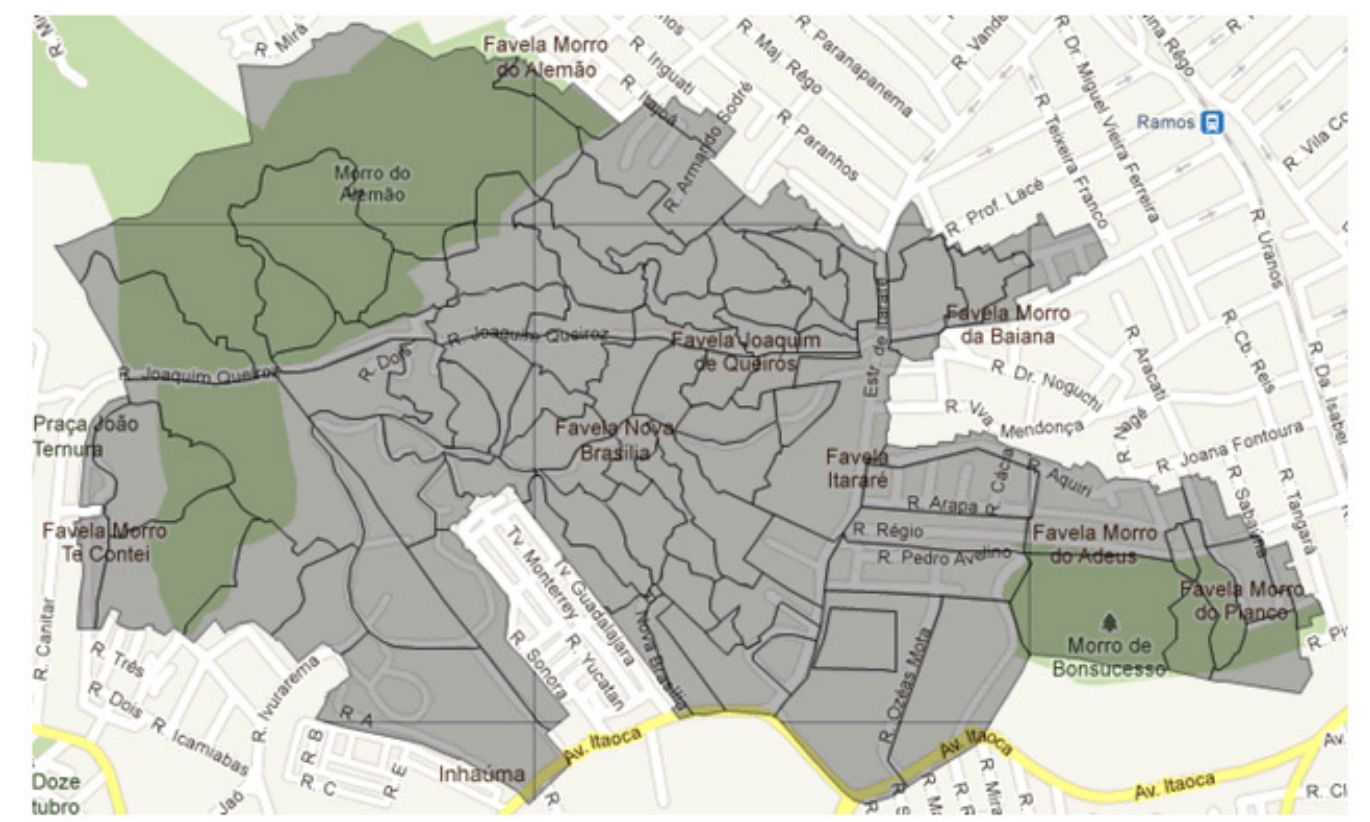

Figura 1: Complexo do Alemão. Fonte: IBGE (2013).

$<$ http://saladeimprensa.ibge.gov.br/noticias?view=noticia\&id=1\&busca=1\&idnoticia=2051> Acessado em 29/05/2013.

Figure 1: Complexo do Alemão. Source: IBGE (2013).

$<$ http://saladeimprensa.ibge.gov.br/noticias?view=noticia\&id=1 \&busca=1 \&idnoticia=2051> Accessed on 29/05/2013

Atualmente, a Serra da Misericórdia é uma Área de Proteção Ambiental e o Programa de Aceleração do Crescimento (PAC) começou suas obras, como por exemplo, o Teleférico inaugurado em 2011. 
Em 2012, o território recebeu as Unidades de Polícia Pacificadora (UPP) e o Complexo do Alemão entrou na agenda do poder público, iniciando-se um amplo processo de transformação do território com base nas políticas públicas federais, estaduais e municipais relacionadas à segurança, que começaram a mudar o cenário deste território.

O Complexo do Alemão apresenta-se como um dos casos emblemáticos relacionado à violência e à tentativa de sua superação no país, principalmente depois do Brasil acompanhar, pela mídia, cenas de "guerra civil" neste local, em 2011. Atualmente, percebe-se uma tentativa de aproximação do Estado, de ONG's e de instituições privadas com o objetivo de promover qualidade de vida aos moradores. É possível dizer que se vive um amplo movimento para promover o desenvolvimento do Complexo do Alemão.

O turismo no Alemão teve início depois da construção do teleférico e ganhou mais força depois do início do processo de pacificação, com vários agentes locais se mobilizando para desenvolver a atividade.

\section{O socioambientalismo e as políticas públicas no campo do turismo}

Em 1986, com a fundação da organização não-governamental SOS Mata Atlântica, uma das ONGs mais atuantes e importantes do país, iniciase uma nova configuração dos movimentos ambientais, passando a agregar ações de caráter ecológico (ambiental) aos movimentos sociais. Juntos, esses dois movimentos formam o que viria a ser chamado de socioambientalismo. Tal movimento se fortalece com a redemocratização do Brasil no fim do regime militar (1985) e impulsiona a Constituição de 1988, considerada marco da descentralização dos poderes no país, também conhecida como "a lei cidadã".

Nesse cenário, Santilli (2005) destaca que a "Aliança dos Povos da Floresta", oficializada em 1989, defendia o modo de vida (cultura) das populações tradicionais amazônicas e estabeleceu as bases do socioambientalismo brasileiro que, segundo a autora, nasceu baseado no pressuposto de que as políticas públicas ambientais só teriam eficacia social e sustentabilidade política se incluíssem as comunidades locais e promovessem uma repartição justa e equitativa dos benefícios derivados da exploração dos recursos naturais. "Trata-se de entender as traduções locais para a ideia de proteção dos recursos naturais" (SANTILLI, 2005, p.35).

Ainda de acordo com Santilli (2005), de alguma forma as hierarquias entre os diferentes "saberes ambientais", até então considerados na percepção de apenas uma determinada classe social, se esfacelam, buscando outras percepções para revelar os usos sustentáveis dos recursos naturais presentes no ambiente. Neste sentido, percebe-se uma aproximação do Estado, da ciência e do poder com o saber local.

Em 1992, com a realização da Rio-92, a Conferência das Nações Unidas sobre Meio Ambiente e Desenvolvimento, considerada marco do ambientalismo internacional e nacional, os valores de participação e descentralização foram reforçados. Igualmente, foram valorizados saberes e direitos locais, com ênfase nas ideias de desenvolvimento sustentável e de 
justiça social. Na Rio+20 foi possível constatar a "Cúpula dos povos" organizando-se para continuar trabalhando nessa perspectiva.

A ideia do sociambientalismo está presente em documentos importantes para proteção e conservação ambiental. O Sistema Nacional de Unidades de Conservação (SNUC), a lei 9.985 (BRASIL, 2000), por exemplo, apresenta no artigo 40 sobre os objetivos, a proteção dos "recursos naturais necessários à subsistência de populações tradicionais, respeitando e valorizando seu conhecimento e sua cultura e promovendo-as social e economicamente".

A referência ao socioambientalismo pode ser identificada, também, no Decreto 4.339 de 2002, que institui diretrizes para implementação da Política Nacional da Biodiversidade, a saber:

\begin{abstract}
XII - a manutenção da diversidade cultural nacional é importante para pluralidade de valores na sociedade em relação à biodiversidade, sendo que os povos indígenas, os quilombolas e as outras comunidades locais desempenham um papel importante na conservação e na utilização sustentável da biodiversidade brasileira;
\end{abstract}

No socioambientalismo florescem ideias de descentralização e desenvolvimento local em um sentido prático e político, correlatas às referidas neste estudo. Assim é que cabe considerar Buarque (2002), ao destacar a questão da endogenia como sustentação para a qualidade de vida de populações fixadas em uma localidade específica e ao ressaltar que a multiplicidade e as sinergias existentes em determinados ambientes são potencialidades que podem contribuir para a formação de um sujeito político.

$\mathrm{Na}$ esteira desse diálogo, cabe considerar a colocação de Santos (2007) ao sugerir uma ecologia de saberes na qual são propostas horizontalidades nos modos de tratar diferentes tipos de conhecimento.

Desse modo, o fazer local pode ser considerado em qualquer tipo de estratégia voltada para o desenvolvimento endógeno, visto que auxilia o crescimento econômico de determinada região, agregando valor à produção local que movimenta sua economia, sendo que esta produção depende de aspectos políticos, socioculturais e tecnológicos. Para Santos, (2007, p.41) "é preciso captar toda a riqueza para não desperdiçar a experiência, já que só sobre a base de uma experiência rica não desperdiçada podemos realmente pensar em uma sociedade mais justa".

Têm-se, portanto, que as discussões que começaram com o movimento socioambiental, atualmente vêm sendo pensadas, também, sob o ponto de vista do desenvolvimento local, independente das localidades analisadas estarem ou não associadas à questão da preservação da natureza. Para Buarque (2002, p.30), o desenvolvimento local depende da capacidade de os atores e as sociedades locais se estruturarem e se mobilizarem, com base nas suas potencialidades e na sua matriz cultural, para definir e explorar suas prioridades e especificidades. 
O processo de desenvolvimento local expresso pelo sociambientalismo encontra, via descentralização, possibilidades de contribuir para a construção de sociedades sustentáveis, criando espaços para decisões autônomas. E os processos de descentralização revelam sua capacidade de transferir o poder de escolha e decisão para comunidades, municípios, o que, segundo Buarque (2002), contribui para a educação política dos cidadãos. Nessa mesma linha interpretativa, Acselrad e Leroy (1999) defendem novas possibilidades para além de uma ideologia do desenvolvimento a qualquer preço e ressaltam a importância de se submeter à razão economicista aos sujeitos sociais, aos seus valores e suas aspirações.

Tais questões relacionam-se com o tema das políticas públicas no campo do turismo, que também cabe aqui considerar, pois são elas que decidem como os recursos públicos serão aplicados e quais as principais estratégias para o desenvolvimento do turismo.

No Brasil, a atividade turística vem se consolidando no campo das políticas públicas, tendo em vista sua grande relevância para o desenvolvimento do país. Em 1994, inicia-se o Programa Nacional de Municipalização de Turismo (PNMT), que visava à formação de multiplicadores das propostas políticas de descentralização via Conselhos Municipais de Turismo.

Entre 2003 e 2007, lança-se o Plano de Desenvolvimento do Turismo (PNT) Nacional baseado também na perspectiva de descentralização e na valorização da participação dos moradores locais, com ênfase na discussão dos planos turísticos de municípios, estados e regiões. Nessa perspectiva, em 2004, ganha destaque o Programa de Regionalização do Turismo.

Já em 2008 passa a vigorar a Política Nacional de Turismo que, no artigo 5 explicita como objetivos: II - reduzir as disparidades sociais e econômicas de ordem regional, promovendo a inclusão social pelo crescimento da oferta de trabalho e melhor distribuição de renda; VI promover, descentralizar e regionalizar o turismo, estimulando Estados, Distrito Federal e Municípios a planejar, em seus territórios, as atividades turísticas de forma sustentável e segura, inclusive entre si, com o envolvimento e a efetiva participação das comunidades receptoras nos benefícios advindos da atividade econômica; VIII - propiciar a prática de turismo sustentável nas áreas naturais, promovendo a atividade como veículo de educação e interpretação ambiental e incentivando a adoção de condutas e práticas de mínimo impacto compatíveis com a conservação do meio ambiente natural e IX - preservar a identidade cultural das comunidades e populações tradicionais eventualmente afetadas pela atividade turística;

Como pode se visualizar, nesta mesma lei, a ideia de descentralização está presente na forma como se pretende organizar a atividade turística no Brasil. O seu art. $8^{\circ}$, que institui o Sistema Nacional de Turismo, por exemplo, reza que o mesmo será composto pelas "instâncias de governança macrorregionais, regionais e municipais".

O Art. 9 apresenta, como um dos objetivos do Sistema Nacional de Turismo, a promoção da regionalização do turismo, mediante o incentivo à 
criação de organismos autônomos e de leis facilitadoras do desenvolvimento do setor, descentralizando a sua gestão.

Também no sítio eletrônico do Ministério do Turismo encontra-se explicitada a forma como as políticas públicas no campo do turismo estão sendo pensadas nessa mesma direção.

O PNT concebeu e o MTur implementou, como base da sua atuação, um modelo de gestão pública descentralizada e participativa, integrando as diversas instâncias da gestão pública e da iniciativa privada, por meio da criação de ambientes de reflexão, discussão e definição das diretrizes gerais para o desenvolvimento da atividade turística do País.

A preocupação com a melhoria das condições socioambientais das localidades permeia todo o discurso dos envolvidos na promoção da atividade turística,sendo uma das propostas a que propõe, por meio da descentralização, a promoção de regiões do interior do país.

Neste contexto, foram propostos nove macros programas para a gestão dos produtos turísticos e da cadeia produtiva a eles relacionada, sendo dois deles diretamente baseados na descentralização ao sugerir transferência dos processos de decisão para as próprias pessoas que trabalham com a atividade turística, de forma direta ou indireta. Este é o caso do Programa de Regionalização que tem como uma de suas missões potencializar os benefícios da atividade para as comunidades locais e integrar e dinamizar os arranjos produtivos do turismo.

A criação do Ministério do Turismo, em janeiro de 2003, trazendo em seu bojo o PNT, configura um marco para o desenvolvimento do setor no Brasil, visto seu propósito de enfrentar, na área do turismo, o desafio de identificar um novo modelo de gestão pública, descentralizada e participativa, de modo a gerar divisas para o país, a criar empregos, a contribuir para a redução das desigualdades regionais e a possibilitar a inclusão dos mais variados agentes sociais.

Neste contexto, o Ministério do Turismo abriu um edital em 2008 que beneficiou vários projetos de turismo de base comunitária, marcando este setor como uma das áreas estratégicas do Ministério do Turismo para o desenvolvimento da atividade turística no Brasil.

\section{A Rede Brasilidade Solidária e o turismo solidário}

A Rede Brasilidade Solidária ${ }^{2}$ foi concebida com a intenção de promover o desenvolvimento local por meio do turismo e de contribuir para minimizar os problemas socioambientais ao formar redes de cooperação e divulgar as localidades que se ancoram nas discussões referentes ao turismo solidário, tendo como pressuposto a ideia de que a formação de redes é parte de um processo de atuação política, pois os participantes convergem em relação às diretrizes teóricas e metodológicas para atuação no campo do turismo. A Rede pretende disseminar uma metodologia que sinaliza para a questão da adoção dos princípios norteadores do socioambientalismo e do desenvolvimento local pelo turismo solidário. Supõe-se que alguns municípios e associações de moradores possuem potencial para investir no turismo. 
A Rede Brasilidade Solidária, em fase de consolidação, tem como material de primeira provocação a apresentação do "Programa Retrato Brasil", que revela os modos de implantação e de organização de determinados formatos de turismo relacionados à ideia do turismo solidário. Faz-se isso pensando que, apesar das oportunidades do cenário turístico, existem muitos grupos e pessoas que têm dificuldade em empreender uma nova atividade nesse segmento.

Com capacidade de alcançar quem não está acostumado a ler teses acadêmicas, esse programa enfatiza a questão da convivência, da emoção e da motivação, fomentando para que surjam novas iniciativas que contribuam para o desenvolvimento local ${ }^{3}$.

Longe das abordagens mecânicas e deterministas, o turismo solidário, trabalhado pela Rede Brasilidade Solidária, sinaliza para o uso da abordagem complexa no campo do turismo e trabalha com os pressupostos metodológicos sistematizados por Fortunato (2011) nos "6Vs" do turismo solidário (visitação, vendas, vivências, vínculos, veiculação, validação), fazendo alusão aos outros campos do conhecimento, como o marketing, que usa a ideia dos Ps (praça, preço, promoção, ponto de venda) e da educação ambiental que usa a ideia dos Rs (repensar, reduzir, reutilizar e reciclar) para suas sistematizações. Os " 6 Vs" são pensados em termos de doação e de recepção simultâneas, ou seja, em termos de interdependência mas, eventualmente, podem ocorrer sozinhos e, não necessariamente, existe uma ordem pré-determinada para se chegar a uma conclusão, apesar da ideia disseminada pela Tecnologia Social (validação) pressupor alguns passos necessários à consolidação do turismo solidário. Têm-se, portanto, uma abordagem para a promoção do turismo, cujos indicadores (Figura 2) e diretrizes sinalizam para a sistematização e o acompanhamento dos processos. A seguir, apresenta-se um resumo de cada um dos "6 Vs" do turismo solidário ${ }^{4}$.

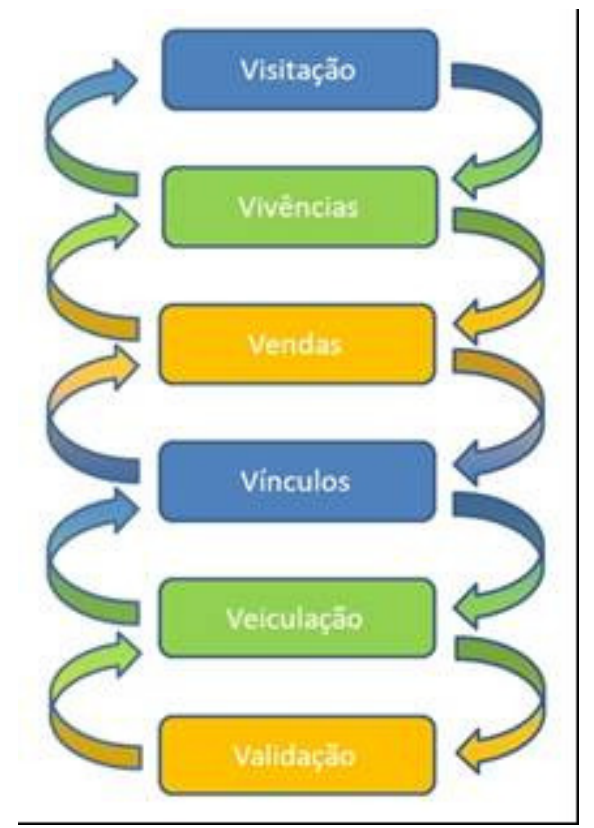

Figura 2: Indicadores do turismo solidário. Fonte: www.brasilidadesolidaria.com. Figure 2: Indicators of solidarity tourism. Source: $\underline{w w w . b r a s i l i d a d e s o l i d a r i a . c o m}$. 


\section{Visitação: roteiros baseados em saberes locais}

Este indicador relaciona-se à visitação impulsionada pela questão do pertencimento e do fortalecimento de uma identidade territorial capaz de mobilizar os atores sociais para alcançarem objetivos comuns. Trabalha-se, predominantemente, com a seguinte questão: a visitação propõe um cardápio de roteiros inovadores baseados em saberes locais e nos envolvimentos em ações sociais e em visitas às associações comunitárias e seus projetos?

Os trabalhos com roteiros baseados em saberes locais proporcionam uma reflexão sobre a história das localidades visitadas, bem como sobre seu diferencial e peculiaridade. Cria-se, desse modo, um ambiente propicio para a valorização do saber local visando ao desenvolvimento local. O estímulo às visitas e aos projetos comunitários é considerado essencial, pois os sujeitos visitados podem sentir-se motivados quando seus trabalhos são reconhecidos pelos turistas que, em alguns casos, se tornam parceiros dos projetos.

A história oral tem se apresentado como uma boa estratégia para pensar uma identidade territorial que dê suporte a uma visitação mais significativa para o turista.

\section{Vivências: aumento no nível de intimidade}

Este indicador relaciona-se às trocas de experiências no campo do turismo, que fazem do mesmo um ambiente propício para o aprendizado mútuo e para a criação de vínculos que sinalizam para posturas solidárias. Procura-se responder a seguinte pergunta: as visitações proporcionam uma convivência de, no mínimo, duas horas por dia do turista com a população local e criam condições para que o nível de intimidade nos encontros aumente?

Parte-se do princípio de que há crescimento da busca por um tipo de turismo que prioriza a convivência com os moradores das localidades visitadas. Os encontros estão se apresentando como um diferencial no campo do turismo, sendo capazes de alargar a percepção do indivíduo por meio de trocas de experiências (FORTUNATO; NEFFA, 2010). Os encontros de indivíduos com diferentes percepções da realidade criam um campo de possibilidade para construção de posturas que prezam pela horizontalidade no campo do saber. Além disso, o maior tempo de permanência dos turistas nas localidades permite que os turistas possam destinar mais recursos aos lugares visitados.

\section{Vendas: campanhas de marketing}

Este indicador procura entender o turismo como um fenômeno social que perpassa o campo da economia e dos negócios, pois alguns atores sociais que compõem a rede podem ter dificuldades financeiras e desejar melhorar sua qualidade de vida por meio do turismo. Sendo assim, faz-se necessário pensar uma estratégia de marketing para posicionamento no mercado e garantia da sustentabilidade econômica da iniciativa. Procura-se 
responder a seguinte questão: as vendas incorporam campanhas de marketing e parcerias institucionais para atrair visitantes?

Trabalha-se com o pressuposto que o conhecimento do perfil dos turistas e o estabelecimento das parcerias institucionais são fundamentais para conseguir apoio para os produtos turísticos a serem comercializados. Constata-se, nesse caso, a importância de se recorrer à ideia de rede para buscar o desenvolvimento local. No ambiente das redes, criam-se sinergias que facilitam a inovação e a promoção das vendas dos produtos turísticos.

\section{Vínculos: economia solidária e arranjos produtivos locais}

O trabalho no campo dos arranjos produtivos locais procura fortalecer a economia da região na qual o turismo ocorre, incentivando o protagonismo histórico e o empreendedorismo para atuação na cadeia produtiva do turismo. No turismo, assim como em outras atividades econômicas, é importante pensar no fortalecimento da região para além do fortalecimento individual, e nesse quesito, os trabalhos no campo da economia solidária são relevantes, pois pretendem unir pessoas que, até então, eram concorrentes e, desse modo, estreitar os vínculos entre os atores sociais que fazem parte da cadeia produtiva do turismo. Trabalha-se na perspectiva da produção da existência, material e espiritual, na qual a reciprocidade e a dádiva (MOUSS, 1974) são consideradas elementos essenciais. O senso comum faz uso desses elementos cotidianamente em várias regiões do Brasil como, por exemplo, no Vale do Jequitinhonha (FORTUNATO, 2011).

A principal pergunta a ser respondida nesse indicador é: há diretrizes indicadoras de trabalhos no campo da economia solidária e dos arranjos produtivos locais?

\section{Veiculação: responsabilidade socioambiental dos empreendimentos}

Com base neste indicador, é possível perceber a importância da responsabilidade socioambiental dos atores sociais envolvidos no campo do turismo para sensibilizar os visitantes em relação aos problemas socioambientais, visto que o turismo é conhecido também por sua degradação social e ambiental ao inserir lógicas de produção e de consumo que não contribuem para minimizar os conflitos socioambientais. Neste indicador, a relevância recai nos trabalhos de educação ambiental e no compromisso dos atores sociais em veicular suas ações. Parte-se do pressuposto defendido por Rorty (2007) de que a linguagem é uma simbolização do real e que a expressão de uma linguagem por meio da veiculação de novos valores cria possibilidades para emersão de novas realidades. Neste indicador, procura-se responder a seguinte questão: informações relacionadas à responsabilidade social dos empreendimentos são disponibilizadas para os turistas? 


\section{Validação: reprodução da tecnologia social}

Um dos principais objetivos da formação de redes é a disseminação da proposta, pois a atuação em redes pressupõe um posicionamento político e ideológico em torno de uma concepção do modo de organização dos produtos turísticos. Acredita-se que os atores sociais, que utilizam como referência o turismo solidário, estão desejosos de trocar experiências em relação às dificuldades e às potencialidades de seus trabalhos para que outros indivíduos possam se beneficiar das experiências.

Acredita-se no caráter interdependente das relações, no qual a excessiva competição e a sua lógica de retenção do saber não ofusca as potencialidades da solidariedade. Nesse indicador, pretende-se esclarecer a seguinte questão: a atividade incorpora uma política na perspectiva do movimento da Tecnologia Social?

Trata-se, nesse ponto, de trabalhar de acordo com a proposta das ecologias de saberes e contra a experiência desperdiçada (SANTOS, 2006).

O 6 V's estão sendo disseminados no âmbito da formação da prática dos atores sociais e acredita-se que tal formação pode contribuir com o desenvolvimento local no Complexo do Alemão.

\section{Os significados do turismo solidário e das ações socioambientais no Complexo do Alemão}

Neste item, apresenta-se o cenário socioambiental no qual se inserem as propostas de turismo solidário e como tais propostas estão sendo apropriadas pelos moradores locais. Apresentam-se, também, as estratégias dos moradores locais para o fortalecimento dos saberes locais, do poder local, via descentralização, e do desenvolvimento local.

\section{Dificuldades para o estabelecimento de vínculos}

Tendo como base os contatos com os principais líderes comunitários do Complexo do Alemão, os presidentes das associações de moradores, ficou evidente que os mesmos se sentem deslocados em relação aos vários projetos que estão sendo aplicados na localidade. Esse fato vem ocorrendo tendo em vista que os proponentes das atividades, em sua grande maioria, não são moradores do Complexo e chegam com "receitas prontas" que pouco contribuem para a mobilização e a emancipação dos moradores e das associações comunitárias.

Vale ressaltar que, além da presença do poder público, algumas organizações não governamentais (ONG's) também têm se interessado a desenvolver atividades no Complexo do Alemão. No entanto, a entrada de tais organizações não ocorre sem causar problemas e indignações aos líderes comunitários, pois muitos ressaltam que as organizações "de fora" estão desmobilizando as associações locais. Segundo um morador, "existe até ONG da Suíça".

O movimento socioambiental destaca a relevância do papel das Ong's, entretanto, atualmente, em alguns casos, como no Complexo do 
Alemão, algumas se apresentam como instituições centralizadoras que dificultam o protagonismo local. Segundo um dos líderes comunitários entrevistados, eles "não entram em parceria com as associações" e, de acordo com outra liderança, "na hora de reclamar eles vão procurar a associação". Um dos líderes comunitários sugeriu que "todas as ONGs para atuar devem ter o aval das Associações", outros duvidam da efetividade das mesmas e ressaltam que "Ong's na comunidade não funcionam", demonstrando a presença de um conflito e dificuldades para 0 fortalecimento dos vínculos.

Com estes fatos, constata-se que as questões centrais apresentadas nas reflexões sobre o socioambientalismo, referentes à consideração dos saberes locais para promoção do desenvolvimento local, não estão sendo premissas de algumas das organizações atuantes no setor, o que provoca desconfiança e afastamentos que dificultam o desenvolvimento do turismo solidário.

\section{A presença do Estado (Visitação, Vivências, Vínculos e Vendas)}

Vários projetos estão sendo implementados no Complexo do Alemão, mas isso não acontece sem impasses com a população supostamente beneficiada, visto que as várias promessas, segundo alguns moradores, "não estão sendo cumpridas".

É importante lembrar que a proposta da SETUR (Secretaria de Turismo do Estado do Rio de Janeiro) de implantar uma agência receptiva no Alemão não é conhecida pelos líderes comunitários e moradores entrevistados, inclusive por um deles, mestre de Capoeira, que frequenta regularmente o espaço da anunciada instalação. Cerca de um ano após a referida entrevista, em conversa com um empresário do setor de turismo que reside e atua no Complexo, ele ressaltou que "a agência do governo não deu certo".

Foi possível constatar que o fortalecimento de vínculos também são dificultados por certos dualismos no campo político, como pode ser observado na seguinte fala de um dos líderes "o palco do governo é o..., o palco da comunidade é o...".

Em muitos casos, o Estado atua de forma pragmática e altera, inclusive, o nome de alguns locais de grande relevância histórica para os moradores, pois, segundo um morador, "mudaram o nome da estação de coqueiro para Itararé e da praça do terço para praça do conhecimento" e pergunta "e nossa história, vai para onde?". Esse fato dificulta o desenvolvimento do turismo e das vivências de turistas.

Mesmo com todas as dificuldades para manter uma ação conjunta, é possível constatar que moradores destacam melhorias do comércio devido a uma maior circulação de pessoas pelo Complexo, fato que contribuiu para a venda de produtos turísticos.

Apesar das limitações e dos conflitos em torno das ações do Estado, os moradores destacam pequenas melhorias com a presença de vários equipamentos sociais, como assistência social e direitos humanos, 
previdência social e uma agência dos Correios com a seguinte inscrição em sua fachada "primeira agência dos Correios em território pacificado".

A maioria dos moradores entrevistados do Complexo do Alemão é favorável à pacificação, mas reclamam constantemente da abordagem violenta da polícia. Um dos líderes comunitários ressaltou que não dá para "cidadão de bem levar tapa na cara, eu não aceito".

\section{Valorização cultural (Visitação e Vivências)}

Nos encontros com professores, membros da direção e líderes comunitários em uma Escola Estadual constatam-se iniciativas para valorização da cultura local, sendo uma das ações denominada "Conheça melhor seu vizinho". Segundo um dos líderes comunitários, "a gente não sabe quem é quem... bom dia, boa tarde não existe mais", e ressalta a importância de "não deixar que nosso cultura seja esquecida" e nessa perspectiva acrescenta que "o meu parente mais próximo era o meu vizinho do lado...tinha essa cumplicidade...dar benção às tias...hoje esse elo dentro da favela está se dissolvendo".

Diante dessa constatação, cogitou-se trabalhar com a instalação de um túnel do tempo na escola. Foi possível perceber certa mobilização em torno desta proposta, pois um dos líderes comunitários ao passar por um morador pergunta sobre as fotos antigas e outro indica em tom interrogativo "sabe quem é que tem muita foto?".

Em um dos caminhos do Alemão passou-se por crianças jogando bolas de gude e um dos visitantes ressaltou que "faz tempo que eu não vejo isso". A diretora da escola comenta sobre a importância de resgatar valores e diz ser a escola uma referência neste quesito.

$\mathrm{E}$, entre falas de que o "povo brasileiro se americanizou muito", um dos líderes comunitários comenta sobre seu projeto de percussão, lança a ideia de se produzir camisetas com fotos do Complexo do Alemão e uma caravana intitulada "Cavaleiros de São Jorge" pela Serra da Misericórdia.

O turismo solidário apresenta-se, portanto, como uma forma de promoção do pertencimento por meio da valorização do saber local, que pode contribuir para o desenvolvimento local. Outro morador entrevistado ressalta que ele dá aula de capoeira no Morro como voluntário, diz que já fez apresentações para "os gringos ver", mas que ainda não possui nenhum tipo de apoio sistemático para o projeto. Ele fez questão de mostrar suas carteiras de mestre de capoeira e dizer que é federado. Tal fato relaciona-se com o campo do reconhecimento e da autoestima, uma das questões centrais quando se discute turismo solidário (FORTUNATO, 2011).

\section{Educação e Autoestima (Vivências, Visitação e Veiculação)}

Os processos relacionados à educação são considerados fundamentais para o desenvolvimento socioambiental do Complexo do Alemão. No entanto, a diretora de uma escola diz que um dos principais 
problemas que ela enfrenta é a evasão escolar e ressalta "existem muitos jovens soltos na favela", ou seja, sem realizar atividades produtivas.

A educação promove o sentimento de pertencimento que se apresenta como essencial para que o processo de descentralização ocorra de modo efetivo e os moradores possam ser sujeitos de sua própria história.

Tal sentimento de pertencimento é incentivado por um dos líderes comunitários locais, quando diz que um dos seus maiores orgulhos foi ter nascido na "região do Coqueiro" e que não gosta de ser chamado de "comunidade" - modo como estão sendo referidas as favelas cariocas mas de morador da favela, pois segundo o mesmo "favela é planta medicinal que salva vidas".

Nesse contexto, é importante ressaltar que houve um plantio simbólico da planta Favela no Complexo do Alemão. Esse mesmo líder comunitário destaca que os jovens "não dão valor nas coisas que possui... isso que a gente está tentando desenvolver neles" e em relação ao projeto de turismo solidário que começou a ser desenvolvido no Complexo ele diz: "eu te falei que nós íamos chegar em algum lugar", demonstrando apostar na atividade.

\section{Mobilização popular (Vínculos e Veiculação)}

Os líderes comunitários e moradores do Complexo estão se organizando para discutir o desenvolvimento local, para isso realizaram o "I Fórum Socioambiental do Complexo do Alemão" em abril de 2012 e decidiram que o mesmo seria um fórum permanente. Esse fórum tinha como um dos seus objetivos representar a "voz da favela na Rio + 20" e participar da "Cúpula dos Povos".

No muro da escola foi escrito a palavra "autonomia" que, em conjunto com a ação do Fórum, indica uma tendência de emancipação, considerada primordial para pensar na descentralização e em projetos de turismo solidário. No entanto, percebe-se que, em alguns casos, a questão política partidária se faz presente e por vezes atrapalha a mobilização popular em torno de projetos de desenvolvimento local.

É importante destacar a necessidade de se praticar um exercício constante para que as ações públicas sejam desvinculadas de interesses particulares, para que os cidadãos se organizem a fim de alcançar objetivos comuns. Outro fato importante em relação à mobilização popular refere-se ao movimento da juventude marcado pela "força jovem do Complexo do Alemão". Constata-se, portanto, que apesar de alguns entraves, existem também potencialidades para o fortalecimento dos vínculos e da veiculação.

\section{Mídias sociais e a produção de documentários (Vendas, Veiculação e Validação)}

Atualmente, a comunicação tornou-se um elemento essencial para o desenvolvimento local ao mobilizar os indivíduos para atuarem em prol da melhoria das condições de vida na favela. Sendo assim, moradores 
investem nas mídias sociais e na criação de sítios eletrônicos na internet para informar aos cidadãos sobre os principais acontecimentos do Complexo do Alemão.

Ao referir-se à utilização dos meios de comunicação de massas, um dos moradores destacou a "Voz do Complexo do Alemão na internet" e disse estar trabalhando no "Portal do Complexo do Alemão". Por outro lado, em conversa com um dos líderes comunitários, sua fala destacou que "a mídia é mais destrutiva do que construtiva", referindo-se à mídia nacional que, ao anunciar violência, não especifica a localidade e "vende" a notícia como sendo do Complexo do Alemão. Logo em seguida, acrescentou que "as coisas boas eles não informam".

Com o objetivo de divulgar e não desperdiçar a experiência, em consonância com a perspectiva de Santos (2007), o documentário intitulado "Turismo Solidário no Complexo do Alemão"5 apresenta o trabalho de turismo solidário desenvolvido no Complexo do Alemão.

\section{Entraves e potencialidades para o desenvolvimento do turismo solidário}

Após a implementação da abordagem metodológica da pesquisaação transdisciplinar no Complexo do Alemão foi possível constatar alguns elementos que podem dificultar e/ou potencializar o desenvolvimento do turismo solidário. Com objetivo de resumir e mapear os elementos acima explicitados, segue a Tabela 1:

Tabela 1: elementos que podem dificultar e/ou potencializar o desenvolvimento do turismo solidário.

Table 1: elements that may hinder and / or enhance the development of solidarity tourism.

\begin{tabular}{|l|l|}
\hline \multicolumn{1}{|c|}{ Entraves } & \multicolumn{1}{c|}{ Potencialidades } \\
\hline Receitas prontas & Segurança pública \\
\hline Falta de parcerias & Melhorias na infraestrutura \\
\hline Disputas político-partidárias & Relações de proximidade entre vizinhos \\
\hline Alteração de nomes das localidades & Valorização do saber local \\
\hline Abordagem violenta da polícia & Sentimento de pertencimento \\
\hline Falta de apoio aos projetos & Criatividade e inovação \\
\hline $\begin{array}{l}\text { Dificuldade para formação de } \\
\text { trabalhadores }\end{array}$ & Reconhecimento e autoestima \\
\hline $\begin{array}{l}\text { Resistência aos trabalhos que } \\
\text { desrespeitam o saber local }\end{array}$ & Organização de movimentos populares \\
\hline
\end{tabular}

Fonte: Fortunato e Neffa, Rio de Janeiro, 2013.

Fonte: Fortunato e Neffa, Rio de Janeiro, 2013. 


\section{O Turismo solidário: uma aposta no campo do socioambientalismo}

O Complexo do Alemão passa, atualmente, por um momento de transição com a implementação de novas ações que contribuem para a melhoria das condições sociais e ambientais locais e para a reflexão sobre elas. Nessa perspectiva, é possível constatar a atuação de várias entidades na região com objetivo de promover sua imagem por meio da atuação no Complexo do Alemão, visto que a veiculação midiática aumentou principalmente depois da exibição da novela "Salve Jorge" e da produção de um vídeo pela cantora Madonna.

A implantação das unidades de Polícia Pacificadoras possibilitaram a entrada de atores sociais externos em um território antes dominado pelo "poder paralelo". Algumas ONG's e projetos socioambientais, que se apoiavam ideologicamente nos conceitos apresentados pelo socioambientalismo e pelo desenvolvimento local, em alguns casos, atuam de forma pragmática e centralizadora.

Depois de mais de um ano de inserção dos pesquisadores no Complexo do Alemão, um novo termo foi cunhado, ainda que de forma improvisada e incipiente, para contribuir com as análises críticas ao campo do socioambientalismo - "socioambientalismo vaidoso", no qual o que mais importa não é a superação dos problemas socioambientais, mas quem ou qual instituição será reconhecida pelas ações realizadas.

Constata-se, portanto, que algumas ações tidas como socioambientais desenvolvidas no Complexo do Alemão não expressam os conceitos do socioambientalismo por promoverem valores de competição baseados no individualismo, que ofuscam as potencialidades das horizontalidades no campo do saber e dos encontros solidários, podendo contribuir para a promoção do desenvolvimento local.

O contato com os atores sociais no Complexo do Alemão propiciou o inicio de um processo de desenvolvimento do Turismo Solidário, pois a ideia é que o turismo contribua para o desenvolvimento local e não se assemelhe ao turismo realizado em outras favelas que pouco contribui para a superação dos problemas socioambientais (FORTUNATO; NEFFA, 2010). Vale ressaltar que a utilização do termo "solidário" não se refere a simples assistencialismo e caridade, mas a uma postura estabelecida nos encontros entre turistas e população local, no qual o turista sente-se acolhido e retribui com ações socioambientais, palestras e recursos financeiros.

Os "6 V's" do turismo solidário possuem potencial para realização das análises e para contribuir com as reflexões sobre os aspectos teóricometodológicos do turismo solidário, pois proporcionam uma visão ampliada dos processos necessários ao desenvolvimento do turismo, apoiados nas discussões do socioambientalismo, do desenvolvimento local e das políticas públicas no campo do turismo.

Em continuidade, um grupo de estudantes de Turismo da Universidade do Estado do Rio de Janeiro realizou, no dia 11 de maio de 2012, um roteiro socioambiental da Serra da Misericórdia marcando o início do turismo solidário no complexo do Alemão. Desde então, já foram organizados mais de 20 passeios com grupos de estudantes e turistas estrangeiros. 


\section{Referências bibliográficas}

BRASIL. Decreto n. 4.339, de 22 de agosto de 2002. Institui princípios e diretrizes para a implementação da Política Nacional da Biodiversidade. Disponível em: $<$ http://www.planalto.gov.br/ccivil 03/decreto/2002/D4339.htm>. Acesso em $15 / 12 / 2013$.

BRASIL. Lei n. 11.771, de 17 de setembro de 2008. Dispõe sobre a Política Nacional de Turismo. Disponível em: <http://www.planalto.gov.br/ccivil 03/ ato2007-2010/2008/lei/l11771.htm>. Acesso em 15/12/2013.

BRASIL. Sistema Nacional de Unidades de Conservação da Natureza SNUC: a lei n. 9.985, de 18 de julho de 2000. Brasília: MMA/SBF, 2000.

ACSELRAD, H.; LEROY, J.P. Novas premissas da sustentabilidade democrática. Rio de Janeiro: FASE, 1999.

BERNARDO, M. Políticas públicas e sociedade civil. In: BURSZTYN, M. (Org.) Dificil sustentabilidade: política energética e conflitos ambientais. Rio de Janeiro: Garamond, 2001, pp. 107-122.

BUARQUE, S.C. Construindo o desenvolvimento local sustentável: Metodologia de planejamento. Rio de Janeiro: Garamond, 2002.

FORTUNATO, R.A; NEFFA, E. Turismo em favelas cariocas: potencialidades de práticas de Educação Ambiental não formal para superação de problemas socioambientais locais. Ambiente \& Educação Revista de Educação Ambiental, Vol. 15, No 2 (2010)

FORTUNATO, R.A. Turismo solidário e a redescrição social no Vale do Jequitinhonha-MG. Tese de Doutorado. PPGMA-UERJ, 2011.

FREIRE-MEDEIROS, B.A. Gringo na laje: produção, circulação e consumo da favela turística. Rio de Janeiro: Editora FGV, 2009.

HUSSERL, E. A ideia da fenomenologia. Lisboa: Edições 70, 2008.

MACHADO, O.V. Pesquisa qualitativa: modalidade fenômeno situado. In: BICUDO, M.A.V e ESPOSITO, V.H.S (Org). A pesquisa qualitativa em educação: um enfoque fenomenológico. Piracicaba: UNIMEP, 1994. P.3546.

MAUSS, M. Ensaio sobre a dádiva. Forma e razão da troca nas sociedades arcaicas. In: Sociologia e Antropologia. São Paulo : Edusp, 1974

PALAVIZINI, R.S. Uma abordagem transdisciplinar à Pesquisa-Ação. Revista Terceiro Incluído. NUPEAT-IESA-UFG,v.2, n.1, jan/jun, 2012, p. 67-85, Artigo 21.

SANTILLI, J. Socioambientalismo e novos direitos. São Paulo: Peirópolis, 2005.

SANTOS, B.S. Renovar a teoria crítica e reiventar a emancipação social. São Paulo: Boitempo, 2007.

THIOLLENT, M. Metodologia da pesquisa-ação. São Paulo: Cortez, 2011. 


\section{Notas:}

${ }^{1}$ Ver maiores informações em www.brasilidadesolidaria.com

2 Para maiores informações sobre a Rede, acesse 0 site: www.brasilidadesolidaria.com

${ }^{3}$ Pode ser visualizado em:

$<$ http://www.youtube.com/playlist?list=PLAFB IfpPfb9yjpN2 m etYEcyDAbr $\underline{\text { wVn }>}$

${ }^{4}$ Os 6 V"s do turismo solidário já foram apresentados em outros artigos, no entanto, como os pesquisadores consideram os mesmos elementos centrais para as análises dos casos ocorridos em diferentes localidades, faz-se necessário explicitá-los novamente com pequenas alterações. Acredita-se que, com tais repetições de análises, o conceito-método do turismo solidário pode tornar-se mais apurado.

${ }^{5}$ Pode ser visualizado em:

$<$ http://www.youtube.com/watch?v=DbK NacX9Zg\&list=TLWS59Lnliah62M

BQVy5SwWdvq9-Bwtm8 >

Rafael Ângelo Fortunato: Universidade do Estado do Rio de Janeiro, Rio de Janeiro, RJ, Brasil.

E-Mail: fortrafa@hotmail.com

Link para o currículo Lattes: http://lattes.cnpq.br/8616988019237581

Elza Neffa: Universidade do Estado do Rio de Janeiro, Rio de Janeiro, RJ, Brasil.

E-Mail: elzaneffa@gmail.com

Link para o currículo Lattes: http://lattes.cnpq.br/0748998065316873

Data de submissão: 29 de maio de 2012

Data de recebimento de correções: 20 de janeiro de 2014

Data do aceite: 20 de janeiro de 2014

Avaliado anonimamente 